\title{
The Impact of Living on House Rent on Household Welfare a Case of Woreda 08, Yeka Sub-City, Addis Ababa, Ethiopia
}

\section{Wasyhun Belay Welle*}

Department of Development Economics, Ethiopian Civil Service University, Ethiopia

"Corresponding author: Welle WB, Department of Development Economics, Ethiopian Civil Service University, Ethiopia, Tel: +251913243956; E-mail: wase.belay12@gmail.com

Received Date: Jul 07, 2018; Accepted Date: Sep 07, 2018; Published Date: Sep 16, 2018

Copyright: (C) 2018 Welle WB, This is an open-access article distributed under the terms of the Creative Commons Attribution License, which permits unrestricted use, distribution, and reproduction in any medium, provided the original author and source are credited.

\begin{abstract}
Since 2005, Addis Ababa has been implementing a large-scale housing program which aims to reduce the housing supply shortage and improve the living standard of the urban low and middle-income households through the construction of condominium houses. This paper evaluates the impact of living on house rent on household welfare using a cross-sectional data from Yeka sub-city, woreda 08 a sample of 354 (192 rented and 162 owners) households. The data generated to meet these objectives were collected via closed ended structured questionnaires and focused group discussion. This study applied descriptive statistics and binary logit model to investigate the impact of living on the rented house on household poverty status (proxy to welfare). The logistic regression model has as the dependent variable the poverty status (poor and non-poor). The explanatory variables household head age, gender, educational level, marital status, employment sector and household housing situation (rented or owned), income level and household size. The result of the econometric model indicates a household living in a rented house is significantly 3.571 times more likely to be poor than owner households; the married couples were found to be 5.228 times more likely poor compared to single household heads; income of the household negatively and household size positively and an education attainment of the household significantly negatively affect the household poverty status. However, there is no statistically significant evidence as for whether the educational level, the age of the household head, employment sector of the household head and gender of the household head affects the household poverty status.
\end{abstract}

Keywords: Poverty; Welfare; Household; Logistic regression; Binary logistic regression

\section{Introduction}

Historically, economists used financial indicators such as household income, GDP, or consumer confidence as measures of welfare. However, it has become increasingly evident that there are a large number of people who are financially well-off but are still not happy with their situation in life. This question of welfare must be rethought and aimed towards measuring the perceived quality of one's situation in life [1]. This study uses this question as a foundation to access urban household welfare. It focuses on the rented households in order to determine the impact which is contributed to his welfare.

Although housing is an integral part of a human settlement that fulfills a basic need and has a profound impact on the quality of life, health, welfare as well as productivity of man; a large proportion of urban residents in less developed countries do not have access to decent housing at an affordable cost. As a result of this, inadequate housing condition has become an intractable challenge that has continued to receive attention from governments, professionals, developers, and individuals in most developing countries [2].

Addis Ababa is a city with various aspects of urban problems, which include among others, severe housing shortage and poor housing, a highly skewed income disparity, deepening poverty, a concentration of low incomes, overcrowded conditions, high rates of unemployment, transport and infrastructure problems and other related urban problems. In Addis Ababa, there is an ever-growing mismatch between the size of the population and its demand for basic services. Housing is one of these services, which has been for long gravely demanded by the public at large [3].

Housing is unique in the central role it plays in the lives of families as "the basic building block for a range of related benefits personal health and safety, employment opportunities, a decent education, security of tenure, and economic security" [4]. Housing has been one of four major pillars of the welfare state. It has always been recognized as comprising a key aspect of everyday life, closely associated with security and with health and well-being. The other three pillars of the welfare state have been social security, health, and education.

Housing accounts for a high proportion of the capital investment component of welfare and is the largest single item in household budgets. It also plays a major part in defining lifestyles [5]. Home property is often the most important asset in a household's portfolio [6]. It is usually the most valuable asset a household owns and the most readily available collateral for borrowing and house are a subject of great risk for house rented household's welfare.

The most expensive item of household expenditure is rent and for many tenant-households, this takes up more than a third of their income. When people live in their own homes they may save on rent payments [7]. Rent fee is critical for each household for many different reasons, but most important for low-income households because it takes a large portion of income this is the drawback to fulfill other basic needs. Spending too much on rent means less money for other necessities, including food, education, and medical care. Some housing specialists suggest that rental housing is affordable if a household 
Page 2 of 8

spends no more than 25 percent of its monthly income on rent. This rule of thumb loses its meaning as you go down the economic ladder, where the only rule is that the poorer you are; the more you are proportionately likely to pay for housing and basic services $[8,9]$.

In Addis Ababa, 300,000 house units are required to meet the housing deficit [10]. 61.25 percent of Addis Ababa household lives in the different form of rented houses. The root of the current housing affordability problem is the lack of low-income housing programs, at the scale necessary to make significant progress in addressing housing needs in addition; the shortage comes from the cause of high population growth and urbanization. In Addis Ababa, there is no question that the demand for affordable housing far exceeds the supply and that much of the current stock of affordable housing. Addis Ababa, like any other developing country, is urbanizing at a very fast rate, the issue of rental housing cannot be ignored any longer.

The most intensively studied household poverty and welfare status include the age of the household head, gender, marital status, employment sector, education level, household characteristics, household size, dependency ratio, and so forth. This study was included in other variables such as income and housing situation.

Considering the increasing number of rented urban households and the invaluable role of housing in meeting urban housing needs, it is important that the government and all stakeholders pay particular attention to this sector. The reality is that millions of households live in rental housing, and at some point, in life, most people need rental accommodation [8]. Purposive selection of the topic is due to the severity of the problem of housing in the whole Addis Ababa as well as Woreda 08 and as housing problem affects the overall socio-economic aspects of a society, assessing such problem is important from development perspectives.

This paper tried to answer the following main questions: First, the impact of living in a rented house on households' welfare status reflection of the research areas and the synergy between living in the rented house and households' poverty status.

The rest of this paper is organized as follows. Section 2 presents the review of the empirical literature while section 3 specifies the econometric model for analyzing the impact of living on house rent on household welfare. In section 4 , we discuss the data sources and provide descriptive statistics for the considered variables. Section 5 presents the empirical results and section 6 concludes the study.

\section{Literature Review}

The studies of the household welfare and poverty have been modeled using two alternative approaches. The first approach employs probit/logit models to examine the probability of households being poor or not. This approach has been widely used in the empirical literature by previous scholars [11-13].

This study adopts consumption as a measure of welfare. The literature review shall, therefore, be limited to studies that have followed the same approach to analyze the household welfare or poverty [14-16]. They are commonly used in the second approach Ordinary Least Squares (OLS) estimation procedure to regress household per capital consumption on a number of factors that contribute to one's welfare. The empirical results from these approaches tend to yield similar results because factors that increase welfare measured by income or consumption should lower the probability of falling into poverty.

\section{Household head characteristics}

Increasing household size raised the probability of being poor in Kenya and South Africa [16,17]. There are findings of dependency ratio in explaining the poverty incidence and household welfare. Found that a higher dependency ratio significantly and positively increases the probability of households plunging into poverty. The inverse relationship between household size and per capital consumption, and by implication the positive relationship between household size and poverty, is a common finding in the empirical literature $[13,18,19]$. Authors they found increasing of household size, there is a decreasing per capital expenditure of consumption [20].

On average homeowners are older than renters (median age of 40 as compared with 36 for renters), rented households have few families (mean family size of 3 as compared with 2.8 for renters), homeowners are 104 percent greater income than renters, and the consumption size of owners are 33 percent greater than renters. The analysis suggests that rented lose opportunities on income generating, consumption size due to cost $[21,22]$.

Employment of the household enhances household welfare. Sekhampu found that employment of the household was negatively associated with the probability of being poor. Similarly, authors found that having at least one household member engaged in formal wage employment led to a significant increase in household welfare in Malawi [16,23]. Thus, marriage reduces the risk of falling into poverty and unmarried individuals and single-parent families are more likely to be poor than their married counterparts.

Gender of the household head was found to influence household welfare and poverty in Kenya female-headed households were more likely to be poor than male-headed households [17]. In other finding household headed by females, reduce the probability of being poor, in Nigeria male-headed households were more likely to be poor than female-headed households $[20,24]$. The other issue that has arisen from past studies is that the relationship between age and poverty may be non-linear, implying that poverty is relatively higher at a young age, decreases at middle age and then increases again at an old age [18,24].

Among the most important variables to explain chronic poverty incidence is the level of education of the household head specifically these studies have observed that ahead of households whose highest educational attainment was at the primary school level, the secondary level, tertiary level was significantly more likely to non-poor than those with no schooling $[12,13,17]$. Reaching a similar conclusion, other studies John, Anyanwu, Fru Awah Wank, Anyanwu observed that higher levels of education tend to improve household welfare $[14,19,24,25]$.

Renters invest less than owners in social capital and local amenities because renters are more geographically mobile but not long-term effects [26,27]. Moreover, there is no evidence that homeowners are more politically involved than renters. Lawrence Yun and Nadia Evangelou, supported Gary Engelhardt the mobility of renters higher than owners frequently, finally the result shows that homeowners move less than renters, and hence are embedded into the same neighborhood and community for a longer period, 5 percent of owner-occupied residents moved, nearly 25 percent of renters changed residential location $[26,27]$. That is, people with the same age, income, and marital status were significantly more likely to change residence in a given year if he or she were a renter rather than a homeowner. 
Citation: Welle WB (2018) The Impact of Living on House Rent on Household Welfare A case of Woreda 08, Yeka Sub-City, Addis Ababa, Ethiopia. J Glob Econ 6: 305. doi:10.4172/2375-4389.1000305

Page 3 of 8

\section{Methodology}

The studies of the household welfare and poverty have been modeled using two alternative approaches. The first approach employs probit/logit models to examine the probability of households being poor. The second alternative approach models the impact on welfare as measured by consumption or income using Ordinary Least Square (OLS). The empirical results from these approaches tend to yield similar results because factors that increase welfare measured by income or consumption should lower the probability of falling into poverty. In this study, the first approach was chosen.

The logistic distribution is also more preferable than the others in the analysis of dichotomous outcome variable, in that it is extremely flexible and easily uses a model from the mathematical point of view and results in a meaningful interpretation [28].
The logit model is a maximum likelihood estimator that allows for estimating the probability that an event occurs or not by predicting a binary dependent outcome from a set of observable independent or predictor variables.

$Y_{i}=\beta_{0}+\beta_{1} X_{1 i}+\beta_{2} X_{2 i} \ldots \ldots \ldots+\beta_{n} X_{n i}+\varepsilon i$

Let us consider a linear regression of the form;

$Y_{i}=$ the outcome variable predicted from the equation

$X_{i}=$ a vector of explanatory variables representing household

$\beta_{S}^{\prime}=$ a vector of regression coefficients to be estimated

$\varepsilon i=$ the error terms

\begin{tabular}{|c|c|c|c|}
\hline Variables & Types & Variable description & Expect sign \\
\hline \multicolumn{4}{|c|}{ Dependent variables } \\
\hline Poverty status & Binary & 1 if poor and 0 if not poor & \\
\hline \multicolumn{4}{|c|}{ Explanatory variables } \\
\hline \multirow{4}{*}{ Age of the $\mathrm{HHH}^{* *}$} & \multirow{4}{*}{ Categorical } & $18-29$ years old & \multirow{4}{*}{$+/-$} \\
\hline & & $30-40$ years old & \\
\hline & & $41-50$ years old & \\
\hline & & Above 51 years old & \\
\hline Gender of $\mathrm{HHH}$ & Binary & $0=$ Female, $1=$ Male & $+/-$ \\
\hline Marital status of $\mathrm{HHH}$ & Binary & $0=$ if single, $1=$ if married & - \\
\hline Household size & Continuous & Total number of members in $\mathrm{HH}$ & + \\
\hline \multirow{3}{*}{ Education of $\mathrm{HHH}$} & \multirow{3}{*}{ Categorical } & Primary school level & \multirow{3}{*}{ - } \\
\hline & & Secondary school level & \\
\hline & & Tertiary level & \\
\hline \multirow{5}{*}{ Household income } & \multirow{5}{*}{ Categorical } & $<3500$ Birr & \multirow{5}{*}{ - } \\
\hline & & 3501-5500 Birr & \\
\hline & & 5501-7500 Birr & \\
\hline & & 7501-9500 Birr & \\
\hline & & > 9501 Birr & \\
\hline \multirow{4}{*}{ Employment sector of $\mathrm{HHH}$} & \multirow{4}{*}{ Categoricalc } & Own business generator & \multirow{4}{*}{$+/-$} \\
\hline & & Government employee & \\
\hline & & Private organization employee & \\
\hline & & Unemployed & \\
\hline Housing situation & Binary & $0=$ if Owned 1=if Rented & $+/-$ \\
\hline
\end{tabular}

Table 1: Description of variables used in the model. 
Logistic regression assumes meaningful coding of the variables. A logistic coefficient is difficult to interpret if not coded meaningfully. The convention for binomial logistic regression is to code the dependent class of interest as 1 and the other as 0 .

\section{Data and Descriptive Statistics}

\section{Data sources}

To achieve the objective of the study, quantitative and qualitative data are gathering from both primary and secondary sources. The primary data was obtained from households through a questionnaire. This helps to get first-hand information from the residents. The secondary data collection constitutes an extensive survey of literature from different sources including books, journals, official documents, websites and reports from the town housing project office, sub-city and Woreda administrations.

\section{Sampling technique, sampling frame, and sample size}

From Table 1 a multi-stage cluster sampling technique was used in choosing a sample of 354 households 162 owned households and 192 rented households for detailed study. The first stage was involved the random selection of sub-city from 10 sub-cities located in Addis Ababa, namely Yeka sub-city. The second stage was involved the random selection of Woreda 08 from 13 Woredas (due to time and budget constraint only one Woreda was selected). The third stage was involved the random selection households house number from the community list. The head of rented and owner households was selected from each stratum by using stratified random sampling and by applying the principle of the proportional sample selection method. Head of households was stratified according to their "ketena" (sub Woreda unit) in order to conduct the survey in the Woreda.

\section{Poverty line calculation}

The poverty line for each rented and owner households were obtained by adding the total expenditure spent on health, education, rent fee, food and non-food, for each of the sampled households, the amount divided for household size here is the assumption of all gender and age group household members consume the same and equal amount of reported expenditure, which was used as a measure of welfare. International poverty line set at $\$ 1.9$ per capital per day for the underdeveloped world, World Bank 2017 which is approximate 1590 Ethiopian Birr per month converted into the current official exchange rate (1\$=27.79 Birr) [29]. A household whose per capital expenditure was below its poverty line was categorized as being poor and that that's per capital expenditure was higher than its poverty line was classified as non-poor.

\section{Variables used in the model}

Poverty (Dependent variable): This study was focused on estimating household welfare status using poverty monetary measures the consumption approach at household levels because is most widely used when measuring poverty. Common practice starts by identifying a single monetary indicator of household welfare. This tends to be either total expenditure or consumption or total income over some period. Income or consumption can be defined in many ways, some far preferable to others and it is widely agreed [30].

\section{Independent (explanatory) variables}

Age of the household head: The age of the household head is an important demographic factor that potentially affects productivity, income and thus consumption. Age increases the poverty status of the household increase due to reduce productivity, large family size and income level [18].

Gender of the household head: In societies where tradition plays a dominant role in the allocation of various tasks, gender has also implications for generating income and education. Custom and tradition also exert differential power relations between men and women which further suppress asset ownership by women. In Kenya female-headed households were more likely to be poor than maleheaded households. In other finding household headed by females, reduce the probability of being poor inverse finding in Nigeria Maleheaded households were more likely to be poor than female-headed households $[17,20,24]$. From such a perspective, the effect of gender on being poor or not is indeterminate depending on contextual factors governing gender issues.

An education level of the household head: It was expected that household head with more education will gain better income and be more efficient than those with less educated. The education status of household heads increases then their educational expenditures also increase the positive relationship between education of household head and whole family's education expenditures and educational status of the household positively related to welfare status of the households $[12-14,19]$.

Housing situation: Living in an owned house make the household free from rent fee, this indicates that household spends more on food, cloth and education as compare to rented households. Paying rent negatively affect the welfare status of the rented household vice versa for owners.

Marital status of the household head: Married couples will be expected to be more concerned about the household welfare and food security and the need to maintain a minimum consumption threshold would lead them to decide to own a house. Moreover, married couples are less mobile and the joint cosigning and responsibility between them could increase the probability of getting a house. Based on income married couples have less probability of being poor.

Employment sector of the household head: Income generation selfemployed business gain much more income and the probability of being poor reduce but the fixed income employment such like local government civil servant challenge to cover all education and food expenditure, therefore, the probability of being poor will be high so indeterminate or ambiguous depending on the contextual sector.

Household income: Family income represents the amount of income the family earns either daily or monthly. It is the amount of income (in Birr) generate from work and any activities. It will be expected that the availability of family income is positively related to welfare.

Household size: A household with more members will be expected to be exposed to consumption shocks and needs additional resources to stabilize their consumption which indicates that when the numbers of people in a room increase then there per capital expenditures decreased. This is because of large family size with the probability of having more dependents positively related to being poor. Household size has the significant negative effect on the welfare status of a household $[16,17,19,20,24]$. 
Page 5 of 8

\section{Descriptive statistics}

In this survey, the majority of the respondents were male $(64.64$ percent), while 35.36 percent were female. The findings indicated that 67.76 percent of rented household heads were male only 32.24 percent are female and the owner households lead by 61.11 percent of the male and 38.9 percent of a female. 67 percent of respondents are married and 31 percent were single or never married 63.93 percent of the rented household head were married 74.69 percent owners are married. 53.04 percent respondents were living in the privately rented house and the rest 46.96 percent are living in owned houses.

29.57 percent of the respondents were aged between 18-29 years, 52.17 percent between 30-40 years, 9.86 percent between $41-50$ years and 8.41 percent above 51 years old. The mean age of both respondents was calculated to be 35 years and it implies that majority of the respondents were still in their economically active age.

It was also observed that 18.55 percent of the respondents are living alone, 43.77 percent of the respondents had household sizes of 2-3 members, 27.54 percent had 4-5 members, 10.15 percent had more than 6 members, respectively. The average household size was $3.31 \mathrm{~m}$ embers. 73.22 percent rented and 50 percent of owner respondents had about 1-3 members in their household which implies that household member size of rented almost 23 percent less than house owner households but 42 percent owners had about 4-6 members that is about 20 percent much more of rented. The average household size was 3.82 members for owners and 2.86 members for rent.

Employment sector of the respondents was distributed as follows; 16.23 percent participated in own business, 41.16 percent were civil servants, 27.54 percent were private organization employees and 15.07 percent were unemployed, respectively. It was also observed that 16.39 percent rented and 16.05 owners were participating on own business, 51.37 percent rented and 29.63 percent owners were civil servants, 25.14 percent rented and 21.6 percent owners were hired in private organization, respectively. Government employment is the main source of households' income and this implies that working in government office had a big chance of living in a privately rented house. 3 percent of rented household head respondents were unemployed but surprisingly 28.4 percent of owners' household heads are unemployed.

13.91 percent of total respondents were earning on average less than 3500 Ethiopian Birr per month, 16.94 percent rented households and 10.5 percent owner households. 24.69 percent of owners were earning more than 9501 Birr per month (12.56 percent rented earned more than 9501 Birr).

\section{Results and Discussions}

The next Table 2 provides the regression coefficient (B), the Wald statistic (to test the statistical significance) and the all-important Odds Ratio (Exp (B)) for each variable category. If the odds ratio $\operatorname{Exp}(B)$ is less than one (i.e., the estimated regression coefficient is negative), then this means that the odds (or the likelihood) of being poor is higher for the reference category. If $\operatorname{Exp}(\mathrm{B})$ is greater than one, then the odds are higher for a particular category as compared to the reference category.

The variable house situation is significant at the 1 percent level of significance (p-value 0.000 ). The odds ratio for the house (1) is 3.571 since the coding house (1) refers to the household who are living in the rented house. The reference category house (0) refers to the household who are living in owned house and $\operatorname{Exp}(\mathrm{B})$ is greater than one the implication is that the household who are living in the rented house is 3.571 times more likely being poor as compared to the household who are living in an owned house, keeping all other covariates constant. Similar finding with housing ownership condition was found to be more important in predicting self- esteem and life satisfaction than income, occupation or education [31].

\begin{tabular}{|c|c|c|c|c|c|c|c|c|}
\hline \multicolumn{9}{|c|}{ Variables in the Equation } \\
\hline & \multirow{2}{*}{ B } & \multirow{2}{*}{ S.E. } & \multirow{2}{*}{ Wald } & \multirow{2}{*}{ df } & \multirow{2}{*}{ Sig. } & \multirow{2}{*}{$\operatorname{Exp}(B)$} & \multicolumn{2}{|c|}{ 95\% C.I.for EXP(B) } \\
\hline & & & & & & & Lower & Upper \\
\hline House (1) & 1.273 & 0.35 & 13.242 & 1 & $0.000^{*}$ & 3.571 & 1.799 & 7.087 \\
\hline Gender (1) & 0.026 & 0.334 & 0.006 & 1 & 0.939 & 1.026 & 0.533 & 1.975 \\
\hline Mst (1) & 1.654 & 0.474 & 12.176 & 1 & $0.000^{*}$ & 5.228 & 2.065 & 13.238 \\
\hline Edulev & -0.625 & 0.339 & 3.405 & 1 & $0.065^{\star \star \star}$ & 0.535 & 0.275 & 1.04 \\
\hline Empsec & & & 4.918 & 3 & 0.178 & & & \\
\hline Empsec (1) & -1.102 & 0.632 & 3.044 & 1 & 0.081 & 0.332 & 0.096 & 1.146 \\
\hline Empsec (2) & -0.223 & 0.614 & 0.132 & 1 & 0.716 & 0.8 & 0.24 & 2.664 \\
\hline Empsec (3) & -0.331 & 0.611 & 0.293 & 1 & 0.588 & 0.718 & 0.217 & 2.381 \\
\hline Age & & & 0.619 & 3 & 0.892 & & & \\
\hline Age (1) & 0.374 & 0.991 & 0.143 & 1 & 0.706 & 1.454 & 0.209 & 10.131 \\
\hline Age (2) & 0.059 & 0.925 & 0.004 & 1 & 0.949 & 1.061 & 0.173 & 6.495 \\
\hline Age (3) & 0.095 & 0.945 & 0.01 & 1 & 0.92 & 1.1 & 0.173 & 7.004 \\
\hline
\end{tabular}


Page 6 of 8

\begin{tabular}{|c|c|c|c|c|c|c|c|c|}
\hline Size & & & 42.187 & 2 & $0.000^{*}$ & & & \\
\hline Size (1) & -6.563 & 1.263 & 26.984 & 1 & $0.000^{*}$ & 0.001 & 0 & 0.017 \\
\hline Size (2) & -4.117 & 1.219 & 11.414 & 1 & $0.001^{*}$ & 0.016 & 0.001 & 0.178 \\
\hline Income & & & 41.516 & 4 & $0.000^{*}$ & & & \\
\hline Income (1) & -1.168 & 0.532 & 4.825 & 1 & $0.028^{* *}$ & 0.311 & 0.11 & 0.882 \\
\hline Income (2) & -2.065 & 0.605 & 11.653 & 1 & $0.001^{*}$ & 0.127 & 0.039 & 0.415 \\
\hline Income (3) & -3.318 & 0.678 & 23.973 & 1 & $0.000^{*}$ & 0.036 & 0.01 & 0.137 \\
\hline Income (4) & -4.182 & 0.712 & 34.515 & 1 & $0.000^{*}$ & 0.015 & 0.004 & 0.062 \\
\hline Constant & 7.219 & 1.493 & 23.382 & 1 & $0.000^{*}$ & 1364.78 & & \\
\hline
\end{tabular}

Table 2: Variables in the equation.

The variable marital status of the household head (mst) is significant at the 1 percent level of significance (p-value 0.000 ). The odds ratio for mst (1) is 5.228 since the coding mst (1) refers to the household head who are married. The reference category mst (0) refers to the household who are single (never married) and $\operatorname{Exp}(\mathrm{B})$ is greater than one the implication is that the household who are married are 5.228 times more likely being poor as compared to the household who are single (never married), keeping all other covariates constant. This implies that household per capital expenditure (poverty line) decrease with the household head become married, i.e., married couples had a chance to build family adding children's then monthly expenditure divided for a large number of household members per capital expenditure also decrease (falling to under poverty line). 65.96 percent married and 71.96 percent single household head was earned just the amount of mean income (between 5500-7500 Birr per month), and in family size perspective 77.3 percent married household head had between 3-5 household members but single household head 79.44 percent had only between 1-2 household members.

These findings are not consistent with those of (White and Rodgers, 2000) marriage reduces the risk of falling into poverty and unmarried individuals and single-parent families are more likely to be poor than their married counterparts. In economic terms, since marriage generally adds a potential earner to the household, it seems obvious that marriage should increase the economic well-being of members of the family, including the children's.

The variable household head education level (edulev) is significant at the 10 percent level of significance (p-value 0.065). An education level of the household head has a positive influence on household welfare and negatively related to poverty status. However, there is no significant difference in the likelihood of being poor between a household head in primary school education level, secondary school education level, and tertiary level, keeping all other covariates constant. Based on largest income level (above 9501 Birr per month) only 14.17 percent of tertiary level household head household were earned (50.2 percent tertiary education level household head employed in government offices), 19.7 percent secondary level household head household and surprisingly 46.87 percent primary education level household head households earned (87.5 percent primary education level household head engaged in own business and generating income from rent).

This is expected as an increase in educational attainments increases the chances of one's absorption in the labour market and increased earnings, further leading to increased welfare. These findings are consistent with those of, Akerele and Adewuyi, Gounder, John, Anyanwu and Fru Awah Wanka, studies have observed that ahead of households whose highest educational attainment was at the primary school level, the secondary level, tertiary level was significantly more likely to non-poor than those with no schooling. Reaching a similar conclusion, other observed that higher levels of education tend to improve household welfare and the analysis suggests that there is a negative relationship between education and poverty, meaning the higher the level of education the lower the probability of being poor, observed that education tend to improve household welfare. The findings also consistent with the most important variables to explain chronic poverty incidence is the level of education of the household head.

In the case of the study area (in general Addis Ababa) there are a lot of unemployed new graduates and the income disparity in terms of salary between each education level does not have differences, the government new small-scale enterprises create job opportunity and means of income for the people who are not complete high school then, there is no significant difference between education level and poverty status of the respondents. According to Addis Ababa public service common public servants starting salary per month before tax for zero-year experience entrants for elementary school level (specially guard and cleaner positions) 780 Birr, for secondary school (postal position) 1072 Birr, for college diploma (specially secretary positions) 1802 Birr, for BA/BSc (social positions) 2748 Birr and for MA/MSc (social positions) 3001 Birr per month (from Woreda payroll). This implies that at each an education attainment the difference in salary is not more than 600 Birr on average before tax.

The variable household size (hsize) is significant at the 1 percent level of significance (p-value 0.000). The category hsize (1) (1-2 household members) is significant at 1 percent level ( $p$-value 0.000 ) and an odds ratio equals to 0.001 . The reference category is household size more than 6 members. Thus, the odds of being poor are 99.9 
Page 7 of 8

percent (=1-0.001) higher for the household who has more than 6 members as compared to the household who has 1-2 members, keeping all other covariates constant. The category hsize (2) (3-5 household members) is significant at 1 percent level ( $p$-value 0.001 ) and has an odds ratio equals to 0.016 . The reference category is household size more than 6 members. Thus, the odds of being poor are 98.4 percent ( $=1-0.016)$ higher for the household who has more than 6 members as compared to the household who has 3-5 members, keeping all other covariates constant.

Household size has a negative effect on welfare. The inverse relationship between household size and per capital expenditure, and by implication the positive relationship between household size and poverty, is a common finding in the empirical literature increasing household size raised the probability of being poor and Ines nurja, they found increasing of household size, there is a decreasing in per capital expenditure.

The variable household income is significant at the 1 percent level of significance ( $\mathrm{p}$-value 0.000 ). The category income (1) (monthly income of household between 3501-5500 Birr per month) significant at the 5 percent level of significance ( $\mathrm{p}$-value 0.028 ) and has an odds ratio equals to 0.311 . The reference category is the monthly income of household less than 3500 Birr. Thus, the odds of being poor are 68.9 percent $(=1-0.311)$ higher for the household who earned a monthly income less than 3500 Birr as compared to the household who earned monthly income between 3500-5500 Birr, keeping all other covariates constant.

The category income (2) (monthly income of household between 5501-7500 Birr per month) significant at the 1 percent level of significance (p-value 0.001 ) and has an odds ratio equals to 0.127 . The reference category is the monthly income of household less than 3500 Birr. Thus, the odds of being poor are 87.3 percent $(=1-0.127)$ higher for the household who earned monthly income less than 3500 Birr as compared to the household who earned a monthly income between 5500-7500 Birr, keeping all other covariates constant.

The category income (3) (monthly income of household between 7501-9500 Birr per month) significant at the 1 percent level of significance ( $p$-value 0.000 ) and has an odds ratio equals to 0.036 . The reference category is the monthly income of household less than 3500 Birr. Thus, the odds of being poor are 96.4 percent $(=1-0.036)$ higher for the household who earned a monthly income less than 3500 Birr as compared to the household who earned monthly income between 7501-9500 Birr, keeping all other covariates constant.

The category income (4) (monthly income of household above 9501 Birr per month) significant at the 1 percent level of significance ( $p$ value 0.000 ) and has an odds ratio equals to 0.015 . The reference category is the monthly income of household less than 3500 Birr. Thus, the odds of being poor are 98.5 percent $(=1-0.015)$ higher for the household who earned a monthly income less than 3500 Birr as compared to the household who earned monthly income above 9501 Birr, keeping all other covariates constant. The result of the logistic regression shows the coefficient of income is statistically significantly negatively related to poverty status (per capital expenditure). Income related to expenditure because when the household income increases the consumption level of household member's increase this implies per capital expenditure also increases.

\section{Conclusions and Policy Implications}

This paper evaluates the impact of living on house rent on household's welfare. It contributes to the impact evaluation of living in the rented house regarding the urban household welfare effects. The paper concludes that living in a privately rented house relates to an incidence of poverty and negatively impact on per capital expenditure (living in rented houses 3.571 times more likely being poor than owners). However, the relationship between living in the privately rented house and poverty (or welfare) implying that poverty is relatively higher at rented households than house owner's household because 28.39 percent of house owners get their major source of income from rent and 16 percent are used their house for such own business generating.

The paper also concludes that marriage plays a negative role in poverty reduction were married couples per capital expenditure decrease with the number of household members increase. Household size positively relates to the incidence of poverty and negatively impact on per capital expenditure. So, given that poverty increases with increases in household size. The situation determined by a number of children and single parent income generating, the single household heads the total expenditure divided for her/him. The paper also concludes that household income level positively relates to welfare and lowers household poverty status. This is expected when the household income level increases the per capital expenditure level also increases, low-income households whose either rented or owners are a high probability for the vulnerability of being poor.

The paper also concludes that an educational attainment positively relates to welfare and lowers household poverty status. This is expected since education enhances human capital and participation in the labor market and may enhance business performance amongst employed households. However, no statistically significant effect was found with regard to gender and age brings no gains in household welfare and poverty. However, the relationship between age and poverty (or welfare) is not significant.

The results of the study indicate that low-income rented households in the study areas have much more cost burden than owners. Income and poverty status of rented household significantly and negatively related so necessary attention to facilitate the low-income housing provision and provide affordable houses to the lower income residents; with improve housing policies and implementation strategies to delivering promising condominium houses for the people and adopt better housing management practice, providing cheap rental houses for civil servants, diversified employment opportunity (basically for women's) to solve welfare problems, intensify family planning services so as to improve knowledge of family planning and knowledge about fertility could have an impact on household size, which is an important determinant of poverty (household welfare).

\section{References}

1. Joshua Johanni (2011) Household welfare: how to measure and index?.

2. Olufemi A (2016) Evaluation of tenants'satisfaction with rental housing in ilesa, osun state, Nigeria. Int J Econ Commer Manag 6: 571-588.

3. Yinebeb G (2015) Major challenges of accessing housing project finance in Addis Ababa, Ethiopia.

4. Stone ME (2004) Shelter Poverty: The Chronic Crisis of Housing Affordability. New Engl J Public Policy 20: 108-119.

5. Kemeny J (2001) Comparative housing and welfare: Theorising the relationship. J Hous Built Environ 16: 53-70. 
Citation: Welle WB (2018) The Impact of Living on House Rent on Household Welfare A case of Woreda 08, Yeka Sub-City, Addis Ababa, Ethiopia. J Glob Econ 6: 305. doi:10.4172/2375-4389.1000305

Page 8 of 8

6. Greenspan and Kennedy (2008) Sources and uses of equity extracted from homes Oxford Review of Economic Policy 24: 120-144.

7. Ruth McLeod and David Satterthwaite. (2004) The Significance of Housing Investment as a Means of Eliminating Poverty, Homeless International, Thailand.

8. UN-HABITAT (2003) Rental Housing-An Essential Option for the Urban Poor in Developing Countries. Nairobi, Kenya, pp: 1-273.

9. UN-HABITAT and UNESCAP (2008) Rental housing: A much neglected housing option for the poor, Housing the Poor in Asian Cities, Quick guide 7, Nairobi, Kenya, pp: 1-34.

10. UN-HABITAT (2011) Condominium Housing in Ethiopia: The Integrated Housing Development Program. Situation analysis of informal settlements in Addis Ababa: Ethiopia.

11. McKenzie D (2005) Measuring inequality with assets indicators, J Popul Econ 18: 229-260.

12. Mok TY, Gan C, Sanyal A (2007) The determinants of urban household poverty in Malaysia. J Soc Sci 3: 190-196.

13. Edoumiekumo S, Karimo T, Tombofa S (2013) Determinants of Households poverty and Vulnerability in Bayelsa State of Nigeria. Int J Humanit Soc Sci Invent 2: 14-23.

14. Akerele D, Adewuyi AS (2011) Analysis and Profiles and Socioeconomic Determinants of Welfare among Urban Households of Ekiti State, Nigeria. J Soc Sci 3: 1-7.

15. Cheema AR, Sial MH (2012) Incidence, Profile and Economic Determinants of Poverty in Pakistan: HIES 2005-06. Manag Sci Eng 6: 120-129.

16. Sekhampu TS (2013) Determinants of Poverty in South African Township. J Soc Sci 34: 145-153.

17. Geda A, Jong N, Kimenyi MS, Mwabu G (2005) Determinants of Poverty in Kenya: A Household Level Analysis. Working Paper Series, Netherlands, pp: 1-25.

18. Datt G, Jolliffe D (2005) Poverty in Egypt: Modelling and Simulation. Econ Dev Cult Change 53: 327-346.
19. Gounder N (2013) Correlates of poverty in Fiji: An analysis of individual, household and community factors related to poverty. Int J Soc Econ 40: 923-938.

20. Xhafaj E, Nurja I (2014) Determination of the key factors that influence poverty through econometric model's. Eur sci j 10: 1-24.

21. Campbell D, Corvalan C (2007). Climate change and developing-country cities: implications for environmental health and equity. Bulletin of the New York Academy of Medicine, J Urban Health 84: 109-117.

22. Campbell JY, Cocco JF (2005) How Do House Prices Affect Consumption? Evidence from Micro Data. NBER W/Paper No. 11534 11-17, New York, 54: 591-621.

23. Mukherjee S, Benson Z (2003) The Determinants of Poverty in Malawi, 1998. World Development, 33: 39-358.

24. John CA (2014) Marital Status, Household Size and Poverty in Nigeria: Evidence from the 2009/2010 Survey Data African Development Review, 26: 118-137.

25. Wanka FA (2014) The impact of educational attainment on household poverty in South Africa: a case study of Limpopo province University of the wastern cape.

26. Yun L, Evangelou N (2016) Social Benefits of Homeownership and Stable Housing. National Association of Realtors, Chicago, US pp:1-19.

27. Engelhardt GV, Eriksen MD, Gale WG, Mills GB (2010) What are the social benefits of homeownership? Experimental evidence for low-income households. 67: 249-258.

28. Gujarati ND (2004) Basic Econometrics. (4th edn.), The McGraw-Hill Companies, New Delhi pp:1-885.

29. World Bank (2017) The World Bank in Comoros.

30. Ravallion S (1992) Poverty comparisons: A guide to concepts and methods. Working paper No. 88. World Bank, Washington DC pp: 1-138.

31. Bentzinger AL, Christine CC (2009) Low-income homeownership: Benefits, barriers and predictors for families in rural areas MA Thesis, Department of Human Development and Family Studies, Iowa State University, pp: 1-107. 